\title{
Anthropometric Profiling of New Zealand Junior Elite Triathletes
}

\author{
Bhargav Dave ${ }^{1,2}$, Asmi Dave ${ }^{3}$, Nilesh Kotecha ${ }^{4}$ Myrtle Oates $^{5}$
}

${ }^{1}$ DPT, Senior Physical Therapist, Manish Therapy Services, Texas, USA

${ }^{2}$ Professor, Srinivas University, Department of Physical Therapy, Mangalore, Karnataka, India

${ }^{3}$ DPT, Physical Therapist, Rehab Care Group East, Louisville, Kentucky, USA

${ }^{4} \mathrm{MD}$, Texas Institute for Spine Care, Houston, Texas, USA

${ }^{5} \mathrm{MD}$, Texas Continual Care, Houston, Texas, USA

\section{Type of article: Original}

\begin{abstract}
Introduction: The triathlon involves a combination of three separate disciplines-swimming, cycling and running. To date, very few studies have been conducted on the anthropometric characteristics of the New Zealand junior elite triathletes. The aim of this study was to determine the correlation between physical traits of calf girth or sum of eight skinfolds (anthropometry) and running or cycling performances in the triathlon event.

Methods: Eleven junior elite triathletes (6 females, 5 males; (Av. age: 17) who were selected for the New Zealand national squad, were examined in this cross-sectional study. All athletes were measured for the complete anthropometric profile, as per the International Society for Advancement of Kinanthropometry (ISAK) guidelines. It was then correlated with the cycling and running performances using interclass correlation (ICC) with $90 \%$ confidence interval (CI) limits.

Results: A non-significant positive correlation observed between eight skinfolds tests on running performance (ICC: $0.10 ; 90 \%$ CI: $-0.68-0.77 ; \mathrm{p}>0.05$ ) and biking performance (ICC: $0.15 ; 90 \% \mathrm{CI}:-0.65-0.79 ; \mathrm{p}>0.05$ ), suggested athletes with greater body fat may render a better athletic performance. Conversely, a significant negative correlation was observed between calf girth and running performance (ICC:-0.66; 90\% CI: -0.94 - $0.12 ; \mathrm{p}<0.05)$ and a non-significant negative correlation was observed between calf girth and cycling performance (ICC:-0.94; 90\% CI: -0.97-0.68; $\mathrm{p}>0.05$ ).

Conclusion: Anthropometric data can help in predicting an ideal body profile. This research indicates the similarities and differences of the New Zealand junior profile and the world junior profile.

Keywords: Body fat, Skinfold, Sport, Anthropometry, Triathletes

\section{Introduction}

The triathlon is a relatively new sport with only three decades of competition at international level. The rate of growth of the triathlon worldwide has been phenomenal. The triathlon involves a combination of three separate disciplines-swimming, cycling and running. The order of events is usually swimming, cycling, and running although some professional sprint triathlons vary. The Olympic distance triathlon includes swimming (1500 meters), cycling (40 kilometers) and running (10 kilometers) (1). The most successful athletes have amorphology of competitors in, such as to the Ironman Triathlon event, as these athletes are usually heavier and have a stronger build. Recognizing current participants with potential in sports is important, and to develop their skills and groom their learning ability has its own importance. In most organizations, top teams are trained by elite players (2). Physiological parameters and anthropometry may guide coaches and trainers in optimizing training and identifying talent (3). However, the coaching staff remains in a dilemma to determine what somatotype, proportions, and shape are best in order to maximize sporting performance (4).
\end{abstract}

\section{Corresponding author:}

Professor Dr. Bhargav Dave, 2804 Field Hollow Dr, Pearland, Texas, USA 77584.

Tel: +1.2484163321, Fax: +1.8887892329, Email: pt.davebhargav@gmail.com

Received: April 02, 2016, Accepted: June 02, 2016, Published: June 2016

iThenticate screening: May 19, 2016, English editing: June 08, 2016, Quality control: June 12, 2016

(C) 2016 The Authors. This is an open access article under the terms of the Creative Commons Attribution-NonCommercialNoDerivs License, which permits use and distribution in any medium, provided the original work is properly cited, the use is non-commercial and no modifications or adaptations are made. 
Earlier, it had been established that body type could play a crucial role in determining the position of players in the game of volleyball. Sports scientists were encouraged to utilize such information while determining the position of a specific program (5). Similar observation were suggested in playing positions for handball players after analyzing anthropometric profiling (6). Height and body mass had been found to be correlated with sprint performance using anthropometric profile for young teen soccer players (7). However, Knechtle (8) noticed that no association existed between total race performance time, body weight loss and skeletal mass. Similarly, in another study Knechtle (9) found that anthropometry and its influence on race were very little on ultra-endurance triathletes in the longest triathlon. While in swimming events, the length of limbs played a more vital role than the frequency of stride or stroke length. On the other hand, body fat was marked negatively as a dead weight that an athlete needs to carry with him or her during the whole event (10). Therefore, there is a need to identify the influence of anthropometric profiling on triathlon events, particularly on running and cycling performances.

Overall, anthropometric characteristics and performances are interlinked in the majority of athletic sports (11). Past studies have been observed at international competition level and with good validity to predict success by using anthropometric characteristics. However, very few studies have been conducted to date on the anthropometric characteristics of the New Zealand junior elite triathletes and little data exists to compare with international data. Therefore, the general objective of this study was to determine the correlation between physical traits of calf girth or sum of eight skinfolds (anthropometry) and running or cycling performance of junior elite triathletes selected for the New Zealand national squad. In addition, we also compared the anthropometric data from our study of New Zealand junior elite triathletes with that of previously published data from the World Elite and World Junior Elite triathletes (4).

\section{Material and Methods}

\subsection{Research design and setting}

This was a cross-sectional study conducted at a sports camp in Hamilton, New Zealand. The study population comprised of junior elite triathletes who were selected for the New Zealand national squad.

\subsection{Sampling}

All junior elite triathletes who were selected for the New Zealand national squad were invited to the camp. Each of them were informed of the anthropometric profile and study investigations in detail. Subsequently, athletes who agreed to be the part of investigation and showed a willingness to sign informed consent were examined in the study.

\subsection{Study variables and measurement tools}

The standard procedure for anthropometric profiling by the International Society for Advancement of Kinanthropometry (ISAK) guideline was followed for each athlete. Performances in events were measured separately.

\subsection{Data collection}

Criterion anthropometrist (ISAK Level 3 Accredited) marked the key anthropometric positions on the triathletes and then directed the athletes towards three stations. This included skinfold ( 8 measurements), length ( 7 measurements), girth (7 measurements), breadths (7 measurements), body weight and height. All triathletes were measured by a trained Anthropometrist (ISAK Level 2), whose technical error was less, than which was recommended by ISAK. A 5-km running performance was measured on two occasions for each athlete. In addition, a 10-km biking performance data was collected separately. Accordingly, the top 5 athletes were identified.

\subsection{Statistical analysis}

All continuous variables of anthropometric profile are presented as standard deviation. The 5-km running time and $10-\mathrm{km}$ cycling time were evaluated as minute:seconds $(\mathrm{m}: \mathrm{s})$. The correlation between anthropometric profile and cycling and running performances were tested using interclass correlation (ICC) along with $90 \%$ confidence interval (CI) limits. The $\mathrm{P}$ value of $<0.05$ was considered as significant correlation. All collected data was compiled on Microsoft Excel 2007, and analyzed using the Statistical Package for Social Sciences (SPSS Inc., Chicago, IL, USA) program, version 15 . 
http://www.ephysician.ir

\subsection{Research ethics}

The participation in the study was voluntary. Prior to anthropometric profile testing, written informed consent was obtained from all participants. Ethical guidelines were followed throughout the study.

\section{Results}

The study included 11 junior elite triathletes (6 females, 5 males; Av. age: 17) who were selected for the New Zealand national squad. The anthropometric data for these triathletes are given in Table 1. Furthermore, the overall performance data for the $5-\mathrm{km}$ run on two occasions and $10-\mathrm{km}$ cycling time trial for top 5 athletes are given in Table 2. The individual body measurements, (i.e. skinfold and girth average) the top 5 triathletes are given in Table 3. The findings of correlation analysis between skinfold measurements and athlete performance data are given in Table 4. Similarly, the findings of correlation analysis between girth measurements and athlete performance data are given in Table 5. Overall, a non-significant positive correlation was observed between the sum of eight skinfolds and running performance (ICC: $0.10 ; 90 \% \mathrm{CI}$ : $0.68-0.77$; $>0.05$ ) as well as cycling performance (ICC: $0.15 ; 90 \%$ CI: $0.65-0.79 ; p>0.05)$, which suggested athletes with greater body fat may have a better athletic performance. Conversely, a significant negative correlation was observed between calf girth and running performance (ICC: -0.66 ; $90 \% \mathrm{CI}:-0.94--0.12 ; \mathrm{p}<0.05)$ and a non-significant negative correlation was observed between calf girth and cycling performance (ICC:-0.94; 90\% CI: $-0.97-0.68$; $>0.05$ ).

Table 1. Anthropometry scores for male and female junior elite triathletes

\begin{tabular}{|l|l|l|}
\hline Measures & Male triathletes $(\mathrm{n}=5)$ & Female triathletes $(\mathrm{n}=6)$ \\
\hline Age $($ year $)$ & $17.4 \pm 0.9$ & $16.8 \pm 1.0$ \\
\hline Height $(\mathrm{cm})$ & $176.4 \pm 3.5$ & $166.8 \pm 6.8$ \\
\hline Body mass $(\mathrm{kg})$ & $63.9 \pm 3.9$ & $54.4 \pm 3.5$ \\
\hline Sum of 8 skinfold $(\mathrm{mm})$ & $43.4 \pm 7.4$ & $67.5 \pm 16.4$ \\
\hline Arm span $(\mathrm{mm})$ & $200.9 \pm 4.0$ & $188.5 \pm 6.8$ \\
\hline Arm length $(\mathrm{cm})$ & $80.2 \pm 1.2$ & $75.7 \pm 3.0$ \\
\hline Forearm length $(\mathrm{cm})$ & $26.2 \pm 0.9$ & $24.6 \pm 1.0$ \\
\hline Hand length $(\mathrm{cm})$ & $20.6 \pm 0.4$ & $19.1 \pm 0.9$ \\
\hline Thigh length $(\mathrm{cm})$ & $48.4 \pm 1.4$ & $46.8 \pm 3.1$ \\
\hline Leg length (cm) & $39.4 \pm 1.5$ & $37.6 \pm 2.7$ \\
\hline Flexed arm length $(\mathrm{cm})$ & $28.8 \pm 0.3$ & $26.6 \pm 1.3$ \\
\hline Forearm girth $(\mathrm{cm})$ & $25.6 \pm 0.8$ & $23.1 \pm 0.8$ \\
\hline Chest girth $(\mathrm{cm})$ & $89.2 \pm 4.0$ & $82.3 \pm 3.9$ \\
\hline Waist girth $(\mathrm{cm})$ & $72.3 \pm 2.8$ & $64.4 \pm 3.2$ \\
\hline Hip girth $(\mathrm{cm})$ & $88.9 \pm 2.8$ & $87.8 \pm 3.1$ \\
\hline Thigh girth $(\mathrm{cm})$ & $51.0 \pm 1.8$ & $51.6 \pm 2.0$ \\
\hline Calf girth (cm) & $35.3 \pm 0.8$ & $33.7 \pm 1.2$ \\
\hline Biacromial breadth & $40.5 \pm 1.7$ & $37.1 \pm 0.9$ \\
\hline Transverse chest breadth & $28.6 \pm 1.3$ & $25.9 \pm 1.1$ \\
\hline Biiliocrestal breadth & $26.2 \pm 1.2$ & $25.6 \pm 2.3$ \\
\hline Humarus breadth & $7.1 \pm 0.4$ & $6.1 \pm 0.1$ \\
\hline Femur breadth & $9.5 \pm 0.3$ & $8.6 \pm 0.4$ \\
\hline & & \\
\hline
\end{tabular}

Table 2. Top 5 athletes based on overall performance time of 5-km running on two occasions and $10-\mathrm{km}$ cycling time trial

\begin{tabular}{|l|l|l|l|l|l|}
\hline $\begin{array}{l}\text { ID } \\
\text { No. }\end{array}$ & $\begin{array}{l}5-\mathrm{km} \text { run time, } \\
\text { Day-1 (m:s) }\end{array}$ & $\begin{array}{l}\text { 5-km run time, } \\
\text { Day-2 (m:s) }\end{array}$ & $\begin{array}{l}10-\mathrm{km} \text { bike performance } \\
\text { time }(\mathrm{m}: \mathrm{s})\end{array}$ & $\begin{array}{l}\text { Mean time In } \\
\text { running }(\mathrm{min})\end{array}$ & $\begin{array}{l}\text { Overall time } \\
(\mathrm{min})\end{array}$ \\
\hline 10 & $14: 16$ & $18: 21$ & $12: 39$ & 16.18 & 44.76 \\
\hline 8 & $19: 55$ & $18: 14$ & $13: 35$ & 19.24 & 51.04 \\
\hline 16 & $19: 09$ & $20: 06$ & $15: 15$ & 19.57 & 54.30 \\
\hline 13 & $17: 33$ & $23: 02$ & $16: 06$ & 20.17 & 56.41 \\
\hline 17 & $19: 20$ & $22: 14$ & $15: 19$ & 21.07 & 56.53 \\
\hline
\end{tabular}


Table 3. Individual body measurements (i.e. girth and skinfold average) of top 5 triathletes' girth and skinfold average

\begin{tabular}{|l|l|l|l|l|l|}
\hline $\begin{array}{l}\text { ID } \\
\text { No. }\end{array}$ & $\begin{array}{l}\text { Average calf girth } \\
(\mathrm{cm})\end{array}$ & $\begin{array}{l}\text { Average calf SF } \\
(\mathrm{mm})\end{array}$ & $\begin{array}{l}\text { Average thigh girth } \\
(\mathrm{cm})\end{array}$ & $\begin{array}{l}\text { Average thigh SF } \\
(\mathrm{mm})\end{array}$ & $\begin{array}{l}\text { Sum of 8SF } \\
(\mathrm{mm})\end{array}$ \\
\hline 10 & 35 & 7.6 & 48.2 & 6.4 & 42 \\
\hline 8 & 36.4 & 6.2 & 48.4 & 8.2 & 43.4 \\
\hline 16 & 32.1 & 12.2 & 49.1 & 21.4 & 89.5 \\
\hline 13 & 32.8 & 9.3 & 47.0 & 15.1 & 79.6 \\
\hline 17 & 33.2 & 6 & 46.5 & 10.8 & 49.8 \\
\hline
\end{tabular}

Table 4. Analysis of correlation between sum of 8 skinfold measurements and performance data

\begin{tabular}{|l|l|l|}
\hline Event & Interclass correlation (ICC) & $90 \%$ confidence interval \\
\hline Run & 0.10 & $-0.68-0.77$ \\
\hline Bike & 0.15 & $-0.65-0.79$ \\
\hline
\end{tabular}

Table 5. Analysis of correlation between girth measurements and performance data

\begin{tabular}{|l|l|l|}
\hline Event & Interclass correlation (ICC) & $90 \%$ confidence interval \\
\hline Run & -0.66 & $-0.94--0.12$ \\
\hline Bike & -0.94 & $-0.99-0.68$ \\
\hline
\end{tabular}

\section{Discussion}

This study was to investigate whether the physical traits of calf girth or sum of eight skinfolds (anthropometry) correlate with running or cycling performances in the triathlon event. From the data, it can be said that athletes with ID number 13 and 17 had a very close overall performance time. Athlete number 13 had a higher thigh girth than athlete number17, and secured a faster time in the 5-km run. Athlete number 17 had a higher calk girth than athlete number 13, and had better cycling performance. These findings indicate a link between girth and performance. However, it should be noted that athlete number10 secured first place in both events despite having a lower calf and thigh girth than athlete number 8 . Moreover, athlete number10 had lower subcutaneous fat than athlete number 8 . These findings indicate that girth and skinfold may not influence the athlete's performance. Additionally, the anthropometric data obtained by Ackland et al. (4) on world elite and world junior triathlons were compared with New Zealand junior triathlons from the present study. New Zealand triathlons were younger than world triathlons (F-2yrs, M-1yrs). New Zealand female athletes had a lower amount of 8 skinfolds by $8 \%$; had a larger arm span by $12 \%$; had about 5\% less chest girth, waist girth, femur breadth, and thigh girth; had a 4\% longer forearm length; and a 3\% longer hand length as compared to the world junior athletes. Similarly, New Zealand male athletes had a lower sum of 8 skinfolds by $17 \%$; had a longer thigh length by $9 \%$; had a lower thigh girth by $5 \%$; a lower chest girth by $6 \%$; a lower waist girth by $4 \%$; and a lower femur breadth by $4 \%$ as compared to the world junior athletes. The stature of New Zealand's athletes was longer than world junior athletes by 3\%. The New Zealand athletes were lighter than the world athletes. In our opinion, the comparison of anthropometric profile between the New Zealand junior triathletes and the world junior triathletes could help in identifying and selecting youth players from schools and the communities. It can be considered as a little step towards an era where sports will select the athlete rather than the athlete select the sport. It can be seen that some landmarks are developing earlier compared to others. Genetic factors may play an important role in it. Overall, the results indicate demands on the game by means of anthropometric data. However, it should also be considered that if only by body shape or by physical characteristic one could determine the success of an athlete, it could be easier to judge the winner. Although many other aspects are involved in it, we are of strong opinion that body structure or shape is a major contributing factor in choosing an athlete.

\section{Conclusions}

The present study investigated whether the physical traits of calf girth or sum of eight skinfolds (anthropometry) correlate with running or cycling performances of junior elite triathletes from New Zealand. The study indicated a correlation between the calf girth and performance, suggesting that the triathletes ran well if they had smaller calves. We believe that anthropometric data can help in predicting the ideal body profile for specific athletic events, and may help in choosing the ideal athlete. 


\section{Acknowledgments:}

Andrea Braakhuis (ISAK level 3 criterion anthropometrist) and Manish Patel (President, Manish Therapy Services).

\section{Conflict of Interest:}

There is no conflict of interest to be declared.

\section{Authors' contributions:}

All authors contributed to this project and article equally. All authors read and approved the final manuscript.

\section{References:}

1) Hirsh A, Levy ST. Biking with particles: junior triathletes' learning about drafting through exploring agentbased models and inventing new tactics. Tech Know Learn. 2013; 18(1): 9-37. doi: 10.1007/s10758-0139199-8.

2) Vayens R, Lenoir M, Williams AM, Philippaerts RM. Talent identification and development programmes in sport current models and future directions. Sports Med. 2008; 38(9): 703-14. doi: 10.2165/00007256200838090-00001. PMID: 18712939.

3) Galy O, Zongo P, Chamari K, Chaouachi A, Michalak E, Dellal A, et al. Anthropometric and physiological characteristics of Melanesian futsal players: a first approach to talent identification in Oceania. Biol Sport. 2015; 32(2): 135-41. doi: 10.5604/20831862.1140428. PMID: 26060337, PMCID: PMC4447759.

4) Ackland TR, Blanksby BA, Landers G, Smith D. Anthropometric profiles of elite triathletes. J Sci Med Sport. 1998; 1(1): 51-6. doi: 10.1016/S1440-2440(98)80008-X. PMID: 9732121.

5) Duncan MJ, Woodfield L, al-Nakeeb Y. Anthropometric and physiological characteristics of junior elite volleyball players. Br J Sports Med. 2006; 40(7): 649-51. doi: 10.1136/bjsm.2005.021998. PMID: 16799112, PMCID: PMC2564319.

6) Ghobadi H, Rajabi H, Farzad B, Bayati M, Jeffreys I. Anthropometry of world-class elite handball players according to the playing position: reports from men's handball world championship 2013. J Hum Kinet. 2013; 39: 213-20. doi: 10.2478/hukin-2013-0084. PMID: 24511357, PMCID: PMC3916924.

7) Mathisen G, Pettersen SA. Anthropometric factors related to sprint and agility performance in young male soccer players. Open Access J Sports Med. 2015; 6: 337-42. doi: 10.2147/OAJSM.S91689. PMID: 26604842, PMCID: PMC4640228.

8) Knechtle B, Kohler G. Influence of anthropometry on race performance in ultra endurance triathletes in the longest triathlon in North America. Int Spor tMed J. 2007; 8(2): 87-96. Available from: http://connection.ebscohost.com/c/articles/26316941/influence-anthropometry-race-performance-ultraendurance-triathletes-longest-triathlon-north-america

9) Knechtle B, Duff B, Amtmann G, Kohlar G. An ultratriathlon leads to a decrease of body fat and skeletal muscle mass: the triple iron triathlon Austria 2006. Res Sports Med. 2008; 16(2): 97-110. doi: 10.1080/15438620701878881. PMID: 18569944.

10) Landers GJ, Blanksby BA, Ackland TR, Smith D. Morphology and performance of world championship triathletes. Ann Hum Biol. 2000; 27(4): 387-400. doi: 10.1080/03014460050044865. PMID: 10942346.

11) Deprez D, Buchheit M, Fransen J, Pion J, Lenoir M, Philippaerts RM, et al. A longitudinal study investigating the stability of anthropometry and soccer-specific endurance in pubertal high-level youth soccer players. J Sports Sci Med. 2015; 14(2): 418-26. PMID: 25983593, PMCID: PMC4424473. 